\title{
FMRpolyG-positive inclusions in CNS and non-CNS organs of a fragile $X$ premutation carrier with fragile X-associated tremor/ataxia syndrome
}

\author{
Ronald AM Buijsen ', Chantal Sellier², Lies-Anne WFM Severijnen', Mustapha Oulad-Abdelghani², Rob FM Verhagen', \\ Robert F Berman ${ }^{3}$, Nicolas Charlet-Berguerand ${ }^{2}$, Rob Willemsen ${ }^{1 \dagger}$ and Renate K Hukema ${ }^{{ }^{*+}+}$
}

Keywords: FXTAS, CGG repeat, FMRpolyG, RAN translation, Gain-of-function, Inclusions

Fragile X-associated Tremor/Ataxia syndrome (FXTAS), a late-onset monogenetic neurodegenerative disorder, is caused by a CGG-repeat expansion (55-200) in the 5' UTR of the fragile-X mental retardation 1 gene (FMR1) on the X-chromosome [1]. The prevalence of the FMR1 premutation (PM) is about 1:855 in males and 1:291 in females [2]. Approximately $45.5 \%$ of male and $16.5 \%$ of female PM carriers older than 50 years will develop signs of FXTAS [3]. In addition to the core features of tremor and gait ataxia, unexplained medical co-morbidities have been reported, including thyroid disease, cardiac arrhythmias, hypertension, migraine, impotence, and neuropathy [4]. PM carriers have increased levels of FMR1 mRNA (2 to 8 fold in leucocytes) and normal to slightly reduced FMR1 protein (FMRP) levels [5]. The current hypothesis is that FXTAS is caused by an RNA gain-of-function mechanism. Ubiquitin-positive intranuclear inclusions, are found in both brain and non-central nervous system (CNS) organs of patients with FXTAS [6,7]. So far, it is not clear whether these inclusions are protective or toxic. Recently, it has been hypothesized that repeat-associated non-AUG (RAN) translation plays a role in disease process and inclusion formation. Todd et al. [8] demonstrated that through initiation at a near-ATG codon located in the 5'UTR of the FMR1 gene a polyGlycinecontaining protein, FMRpolyG, is expressed. This protein accumulates in ubiquitin-positive inclusions in Drosophila, cell culture, mouse disease models and brain from FXTAS patients. To investigate the link between FMRpolyG

\footnotetext{
* Correspondence: r.hukema@erasmusmc.nl

${ }^{\dagger}$ Equal contributors

'Department of Clinical Genetics, Erasmus, MC, PO Box 2040, 3000CA, The Netherlands

Full list of author information is available at the end of the article
}

expression and the co-morbid medical problems associated with the PM we have developed two novel mouse monoclonal antibodies against polyGlycine; $8 \mathrm{FM}$ and 9FM (for epitopes and specificity see Additional file 1: Figure S1), and performed immunostaining in CNS as well as in non-CNS organs of FXTAS patient J.L. (case 6 in [7]; other cases not available). To establish antibody specificity, we performed immunostaining with both antibodies on brain sections from FXTAS patient J.L., healthy non-demented controls $(\mathrm{n}=3)$ and a patient with Parkinson disease, Alzheimer disease, or C9FTD. In hippocampus and cerebellum from FXTAS patient J.L. we identified FMRpolyG-positive inclusions with both 8FM (1:10) and 9FM (1:10) antibody (Figure 1a-b, Additional file 2: Figure S2a-b), as was described previously [8]. None of the controls showed FMRpolyGpositive inclusions (data not shown). Next, we studied the immunolocalization of FMRpolyG protein in heart, kidney, adrenal gland and thyroid in patient J.L. with 8FM (1:10) and 9FM (1:10), compared to post mortem non-CNS somatic organ tissues from 3 healthy controls. We also examined tissues for FMRP (mouse T1A; 1:200) expression and ubiquitin-positive inclusions (DAKO, ZO458; 1:200). Consistent with our previous report [7], ubiquitin-positive intranuclear inclusions were identified along with a normal distribution of FMRP (data not shown). Intranuclear FMRpolyG-positive inclusions could be detected in all organs examined (Figure 1c-h, Additional file 2: Figure S2c-h). No control tissues showed any FMRpolyG-positive inclusions (data not shown). Colocalization of ubiquitin- and FMRpolyG-positive inclusions was visualized and quantified by immunofluorescent double staining using antibodies against ubiquitin and FMRpolyG 

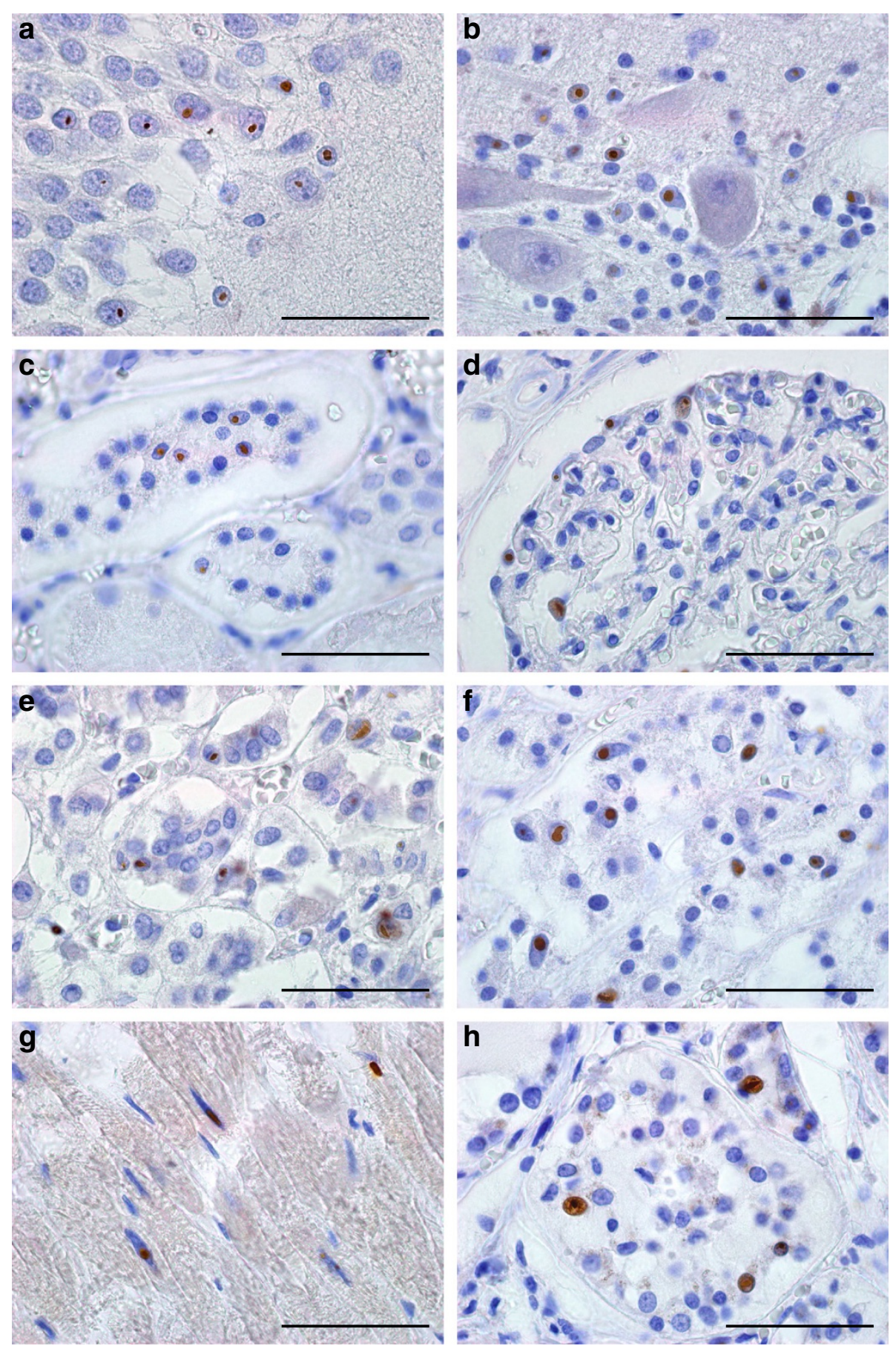

Figure 1 9FM FMRpolyG-positive intranuclear inclusions in hippocampus, cerebellum and non-CNS tissues of a FXTAS patient.

FMRpolyG-positive (9FM) intranuclear inclusions in a hippocampus, b cerebellum, c glomeruli and $\mathbf{d}$ distal tubule of the kidney, e zona glomerulosa and $\mathbf{f}$ zona reticularis of adrenal gland, $\mathbf{g}$ cardiomyocytes and $\mathbf{h}$ thyroid. All sections were immunostained with 9FM antibody and counterstained with hematoxylin. Scale bars represent $50 \mu \mathrm{m}$.

(8FM) (Figure 2a-f). For hippocampus, cerebellum and the non-CNS organs most inclusions are positive for both FMRpolyG and ubiquitin, although some rare inclusions positive for only one of the proteins could also be detected (Figure 2g, $\mathrm{n}=100$ inclusions). In conclusion, using two novel antibodies the present report not only confirms the existence of FMRpolyG-positive aggregates in CNS tissue from a FXTAS individual but also demonstrates for the first time the presence of FMRpolyG-positive intranuclear inclusions in post mortem non-CNS material of a PM carrier 

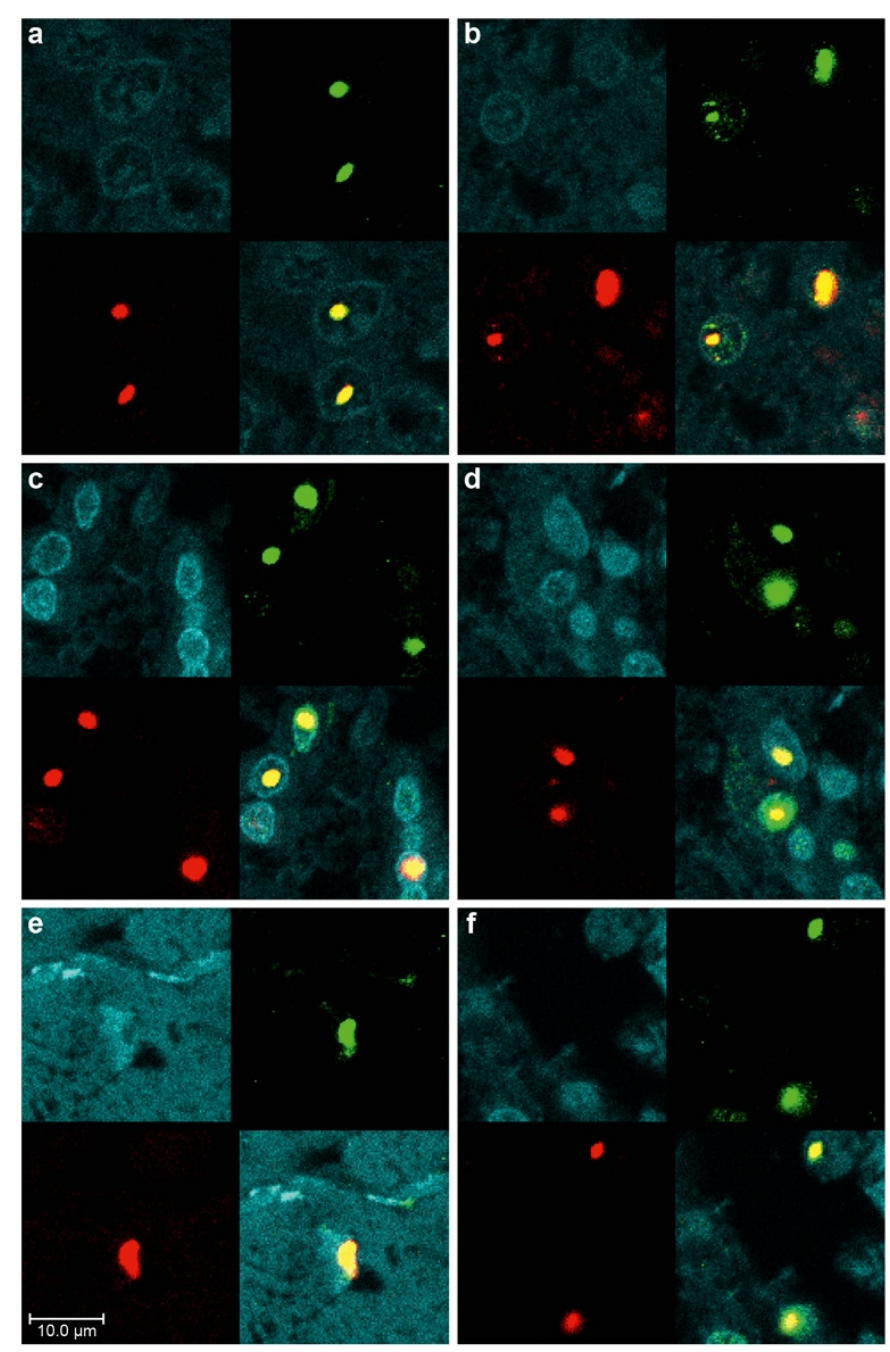

g

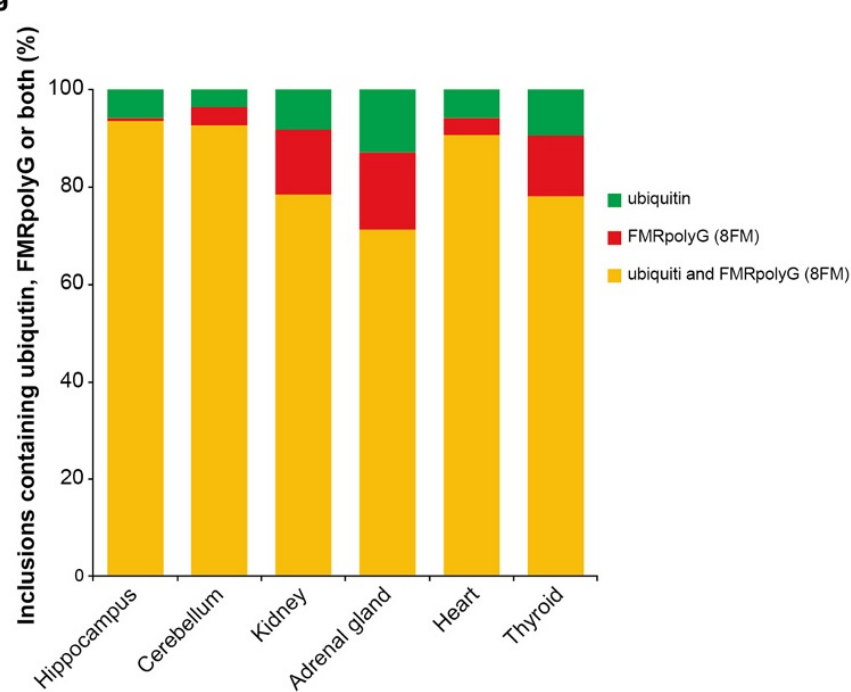

Figure 2 (See legend on next page.) 
(See figure on previous page.)

Figure 2 Colocalization of FMRpolyG (8FM) and ubiquitin in intranuclear inclusions in hippocampus, cerebellum and of non-CNS tissues of a FXTAS patient. Staining for ubiquitin (green), FMRpolyG (8FM; red) and DAPI (blue). Colocalization of ubiquitin and FMRpolyG (yellow) is seen in a hippocampus, $\mathbf{b}$ cerebellum, c kidney, $\mathbf{d}$ adrenal gland, e cardiomyocytes, and $\mathbf{f}$ thyroid; $\mathbf{g}$ quantification of inclusions containing ubiquitin and/or FMRpolyG $(n=100)$. Scale bars represent $10 \mu \mathrm{m}$.

with FXTAS. Furthermore, colocalization of FMRpolyG and ubiquitin is found in the vast majority of inclusions. The presence of FMRpolyG-positive intranuclear inclusions in heart, kidney, adrenal gland and thyroid is consistent with the unexplained medical co-morbidities reported in some patients with FXTAS, including thyroid disease, cardiac arrhythmias, hypertension, migraine, impotence, and neuropathy. We hypothesize that the underlying pathological mechanisms of the medical co-morbidities in systemic tissues share common features (protein toxic gain-of-function) with CNS pathology of patients with FXTAS. Our report suggests that in addition to elevated levels of FMR1 mRNA containing an expanded CGG repeat, and ubiquitin-positive inclusions, FMRpolyG expression might also play a role in a toxic gain-offunction mechanism in medical co-morbidities in FXTAS (RNA versus FMRpolyG toxic gain-of-function). Interestingly, a very recent report suggests that RAN translation products in C9FTD/ALS, toxic dipeptide repeat proteins (poly-(glycine-arginine) and poly-(proline-arginine)), are toxic in Drosophila [9]. Further research is needed to understand how FMRpolyG may elicit toxicity in both CNS and non-CNS organs and its precise role in co-morbidities in PM carriers. Importantly, if FMRpolyG production is important for cellular toxicity this will open new avenues for therapeutic intervention studies for FXTAS by developing drugs that block this aberrant translation.

\section{Additional files}

Additional file 1: Figure S1. Epitopes and specificity FMRpolyG antibodies 8FM and 9FM. a Sequence of the $5^{\prime} \mathrm{UTR}$ of human FMR1 gene and the FMRpolyG peptide sequence resulting from RAN translation. Epitopes of 8FM and 9FM antibodies are boxed. b Monoclonal 8FM and 9FM antibodies were validated on COS7 cells transfected with pEGFP (Clonetech) plasmid containing the 5'UTR of FMR1 with 50 CGG repeats, thus expressing the polyGlycine protein fused to GFP. On Western Blot a specific product could be detected for both antibodies and no product was detectable in COS7 cells transfected with a control GFP plasmid. c As an additional control experiment we performed immunostainings for 8FM antibody and could demonstrate specific intranuclear inclusions in COS7 cells transfected with a construct expressing the FMRpolyG fused to GFP, while cells tranfected with only GFP did not show any inclusion formation. Identical results were obtained with 9FM antibody (data not shown).

Additional file 2: Figure S2. 8FM FMRpolyG-positive intranuclear inclusions in hippocampus, cerebellum and non-CNS tissues of a FXTAS patient. FMRpolyG-positive (8FM) intranuclear inclusions in a hippocampus, b cerebellum, c glomeruli and d distal tubule of the kidney, e zona glomerulosa and $\mathrm{f}$ zona reticularis of adrenal gland, $\mathrm{g}$ cardiomyocytes and $\mathrm{h}$ thyroid. All sections were immunostained with $8 \mathrm{FM}$ antibody and counterstained with hematoxylin. Scale bars represent $50 \mu \mathrm{m}$.

\section{Abbreviations}

ALS: Amyotrophic lateral sclerosis; C9FTD: Chromosome 9 open reading frame 72 frontotemporal dementia; CNS: Central nervous system; FMR1: Fragile-X mental retardation 1; FMRP: Fragile- $X$ mental retardation 1 protein; FXTAS: Fragile $X$-associated Tremor/Ataxia syndrome; PM: Fragile-X mental retardation 1 premutation; RAN: Repeat-associated non-AUG.

\section{Competing interests}

The authors declare that they have no competing interests.

\section{Authors' contributions}

RAMB performed immunostainings and imaging, interpreted results, and drafted the manuscript. CS developed and validated antibodies. LAS performed immunostainings and imaging, and interpreted results. MOA developed and validated antibodies. RFMV performed immunostainings and imaging, and interpreted results. RFB interpreted results, drafted the manuscript and, obtained funding. NCB developed and validated antibodies, interpreted results, drafted the manuscript, and obtained funding. RW interpreted the results, drafted the manuscript, supervised the study, and obtained funding. RKH interpreted the results, drafted the manuscript, supervised the study, and obtained funding. RW and RKH contributed equally to this work. All authors read and approved the final manuscript.

\section{Acknowledgements}

The authors wish to acknowledge the contribution of Tom de Vries Lentsch and Nathan Wubben. This work was supported by the Dutch Brain Foundation project number 2012(1)101 and French Muscular Dystrophy Association project number 16649 [to RW], by the National Institutes of Health grant number NINDS NS079775 [to RFB and RW], by E-Rare project number 40-42900-98-1001/113301201 from ZonMW [to RKH], by E-Rare "CURE FXTAS" from ANR [NCB] and ERC "RNA DISEASES" [NCB].

\section{Author details}

Department of Clinical Genetics, Erasmus, MC, PO Box 2040, 3000CA, The Netherlands. ${ }^{2}$ Department of Neurobiology and Genetics, IGBMC, INSERM U964, CNRS UMR7104, University of Strasbourg, Illkirch, France. ${ }^{3}$ Department of Neurological Surgery, UC Davis, Davis, CA 95618, USA.

\section{Received: 8 October 2014 Accepted: 8 November 2014}

\section{.}

References

1. Hagerman RJ, Leehey M, Heinrichs W, Tassone F, Wilson R, Hills J, Grigsby J, Gage B, Hagerman PJ (2001) Intention tremor, parkinsonism, and generalized brain atrophy in male carriers of fragile $X$. Neurology 57(1):127-130

2. Hunter J, Rivero-Arias O, Angelov A, Kim E, Fotheringham I, Leal J (2014) Epidemiology of fragile $X$ syndrome: a systematic review and meta-analysis. Am J Med Genet A 164(7):1648-1658

3. Rodriguez-Revenga L, Madrigal I, Pagonabarraga J, Xuncla M, Badenas C, Kulisevsky J, Gomez B, Mila M (2009) Penetrance of FMR1 premutation associated pathologies in fragile X syndrome families. Eur J Hum Genet 17(10):1359-1362

4. Willemsen R, Levenga J, Oostra B (2011) CGG repeat in the FMR1 gene: size matters. Clin Genet 80(3):214-225

5. Tassone F, Hagerman RJ, Taylor AK, Gane LW, Godfrey TE, Hagerman PJ (2000) Elevated levels of FMR1 mRNA in carrier males: a new mechanism of involvement in the Fragile-X syndrome. Am J Hum Genet 66(1):6-15

6. Greco CM, Hagerman RJ, Tassone F, Chudley AE, Del Bigio MR, Jacquemont S, Leehey M, Hagerman PJ (2002) Neuronal intranuclear inclusions in a new cerebellar tremor/ataxia syndrome among fragile $X$ carriers. Brain 125(Pt 8):1760-1771

7. Hunsaker MR, Greco CM, Spath MA, Smits AP, Navarro CS, Tassone F, Kros JM, Severijnen LA, Berry-Kravis EM, Berman RF, Hagerman PJ, Willemsen R, 
Hagerman RJ, Hukema RK (2011) Widespread non-central nervous system organ pathology in fragile X premutation carriers with fragile X-associated tremor/ataxia syndrome and CGG knock-in mice. Acta Neuropathol 122:467-479

8. Todd PK, Oh SY, Krans A, He F, Sellier C, Frazer M, Renoux AJ, Chen KC, Scaglione KM, Basrur V, Elenitoba-Johnson K, Vonsattel JP, Louis ED, Sutton MA, Taylor JP, Mills RE, Charlet-Berguerand N, Paulson HL (2013) CGG repeat-associated translation mediates neurodegeneration in fragile $X$ tremor ataxia syndrome. Neuron 78(3):440-455

9. Mizielinska S, Gronke S, Niccoli T, Ridler CE, Clayton EL, Devoy A, Moens T, Norona FE, Woollacott IO, Pietrzyk J, Cleverley K, Nicoll AJ, Pickering-Brown S, Dols J, Cabecinha M, Hendrich O, Fratta P, Fisher EM, Partridge L, Isaacs AM (2014) C9orf72 repeat expansions cause neurodegeneration in Drosophila through arginine-rich proteins. Science 345((6201):1192-1194, doi:10.1126/science. 1256800

doi:10.1186/s40478-014-0162-2

Cite this article as: Buijsen et al:: FMRpolyG-positive inclusions in CNS and non-CNS organs of a fragile $\mathrm{X}$ premutation carrier with fragile $\mathrm{X}$-associated tremor/ataxia syndrome. Acta Neuropathologica Communications 2014 2:162.

\section{Submit your next manuscript to BioMed Central and take full advantage of:}

- Convenient online submission

- Thorough peer review

- No space constraints or color figure charges

- Immediate publication on acceptance

- Inclusion in PubMed, CAS, Scopus and Google Scholar

- Research which is freely available for redistribution 